\title{
ANALISIS TEGANGAN GESER, MOMEN DAN TEGANGAN LENTUR MAKSIMUM UNTUK PEMBUATAN PISAU PADA RANCANG BANGUN MESIN PEMECAH BUAH KAKAO KAPASITAS 2 TON/JAM
}

\author{
Wahyu Hidayat ${ }^{1)}$, Asifa Asri $^{2}$, Eddy Kurniawan $^{1)}$ \\ 1) PRODI TEKNIK MESIN FAKULTAS TEKNIK UNIVERSITAS TANJUNGPURA \\ ${ }^{2)}$ PRODI FISIKA FAKULTAS MATEMATIKA DAN ILMU PENGETAHUAN ALAM UNIVERSITAS \\ TANJUNGPURA \\ Jalan Prof. Dr. H. Hadari Nawawi, Pontianak 78124 \\ Telepon: +62-561-7053252, Fax: +62-561-740187 \\ E-mail :ingga.wahyu@yahoo.com
}

\begin{abstract}
Abstrak
Perancangan dan pembuatan mesin pemecah kulit buah kakao pada penelitian ini memiliki tujuan untuk mendapatkan sebuah mesin dengan kinerja handal serta harga yang terjangkau oleh para petani khususnya para petani coklat di Indonesia. Mesin dirancang dengan sistem portable dengan tujuan mempermudah dalam proses bongkar pasang dan melakukan perawatan. Pisau potong dibuat dengan sistem ulir menggunakan baja ST-45. Hal ini dilakukan untuk mengantisipasi terjadinya patah pada bagian mata pisau. Jika terjadi patah pada mata pisau maka pergantian hanya dilakukkan pada bagian mata pisaunya. Proses pergantian dilakukan dengan ekonomis, apabila dibandingkan mengganti satu set komponen mata pisau dan dudukan. Bagian paling kritis pada mesin ini adalah bagian pisau potong. Pisau potong mengalami tumbukan langsung dengan buah kakao saat proses pemecahan buah kakao, sehingga peluang mengalami kerusakan sangat tinggi dibandingkan bagian mesin lainnya. Hal ini menjadi pertimbangan pisau potong dibuat dengan sistem ulir. Hasil penelitian menunjukkan tegangan lentur maksimum yang terjadi pada pisau potong sebesar $14,3 \times 10^{6} \frac{\mathrm{kg}}{\mathrm{mm}^{2}}$, momen lentur maksimum yang terjadi $180 \mathrm{~J}$, dan tegangan geser maksimum yang terjadinya $1200 \mathrm{~N}$. Penggunaan material baja ST-45 dinilai tepat digunakan dalam perancangan dan pembuatan mata pisau dilihat dari tegangan lentur dan proses pembuatannya menggunakan proses permesinan.

Kata kunci : Pisau Potong, Tegangan Geser Maksimum, Momen Lentur Maksimum, Tegangan Lentur Maksimum, Portable, Rancang Bangun.
\end{abstract}

\section{1 |Diselenggarakan dalam rangkaian Dies Natalis Universitas Tanjung Pura Pontianak/tahun/volume}


Seminar Nasional Penerapan Ilmu Pengetahuan dan Teknologi (PIPT)

\section{Pendahuluan}

Proses pengolahan kakao akan menentukan kualitas akhir dari buah kakao. Pengolahan buah kakao lebih lanjut dilakukan dengan pemeraman buah yang dilakukan selama 5-12 hari, tergantung derajat kemasakan buah dan keadaan iklim setempat. Buah yang diperam tidak boleh terlalu masak, rusak atau diserang oleh cendawan. Buah yang diserang cendawan tersebut masih bisa menghasilkan biji bermutu baik asalkan kerusakannya tidak terlalu besar dan cendawan belum menyerang bagian biji kakao. Serangan cendawan ini sering terjadi pada buah yang retak atau pecah dan kerusakan biji dapat diketahui pada saat pemecahan kakao. Pemecahan kakao harus dilakukan dengan hati-hati agar tidak merusak keping biji. Pemecahan kakao dapat dilaukan dengan alat pemukul, sabit, atau saling memukulkan buah yang satu dengan yang lainnya (Susanto, 1994).

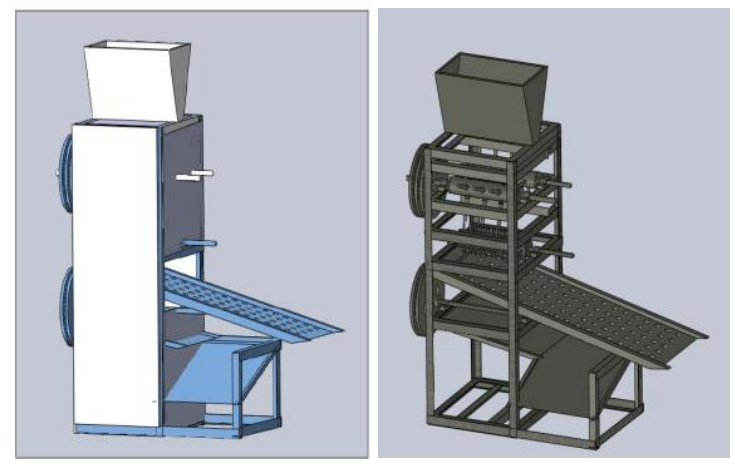

Gambar 1. Mesin Pemecah Buah Kakao Kapasitas 2 Ton Per-Jam
Pemecahan atau penghancuran zat padat merupakan suatu proses yang meliputi semua cara yang digunakan dimana partikel zat padat dipotong dan dipecahkan menjadi kepingan-kepingan yang lebih kecil. Pada industri pengolahan pemecahan atau penghancuran zat padat diperkecil dengan berbagai cara sesuai dengan kebutuhan yang berbeda-beda. Empat cara yang lazim dilakukan dalam proses penghancuran dan penghalusan diantaranya tekanan, pukulan atau impak, pemotongan, gesekan atau atrisi.

Pada penelitian ini digunakan pukulan atau impak dalam proses pemecahan buah kakao. Gaya rata-rata pematahan buah kakao yang tertinggi diperoleh pada buah kakao yang berwarna kuning pada alur yaitu $800 \mathrm{~N}$ sedangkan gaya rata-rata pematahan buah kakao yang terendah diperoleh pada buah kakao yang berwarna kuning pada seluruh permukaan buah yaitu 453,33 N. Jadi semakin matang buah kakao maka semakin lunak kulit buah kakao sehingga gaya yang dibutuhkan untuk mematahkan semakin kecil (Khadijah, 2006). Tekanan rata-rata yang dibutuhkan untuk mematahkan buah kakao tertinggi diperoleh pada buah kakao yang berwarna kuning pada alur yaitu

\section{2 |Diselenggarakan dalam rangkaian Dies Natalis Universitas Tanjung Pura Pontianak/tahun/volume}


Seminar Nasional Penerapan Ilmu Pengetahuan dan Teknologi (PIPT)

$58,53 \mathrm{kN} / \mathrm{m}^{2}$ sedangkan tekanan yang paling rendah diperoleh pada buah kakao yang matang sempurna (seluruh permukaan berwarna kuning) yaitu 34,19 $\mathrm{kN} / \mathrm{m}^{2}$ (Khadijah, 2006).

\section{Metodologi}

Dalam pembuatan mesin pemecah buah kakao dibutuhkan komponen serta material yang digunakan untuk terciptanya mesin ini, sehingga bisa beroperasi dengan baik. Pemilihan material menjadi salah satu faktor yang penting dalam suatu perancangan dan pembuatan produk sehingga memerlukan berbagai pertimbangan yang mempengaruhi kualitas, umur, dan biaya dari pembuatan mesin. Material yang digunakan pada perancangan dan pembuatan mesin ini termasuk pada baja karbon sedang karena akan diproses lebih lanjut dengan proses permesinan. Besi dan baja merupakan logam yang banyak digunakan dalam dunia teknik dan meliputi $95 \%$ dari seluruh produksi logam dunia. Untuk penggunaan tertentu, besi dan baja merupakan satu - satunya logam yang memenuhi persyaratan teknis maupun ekonomis. Dalam pembuatan mesin ini sebagian besar menggunakan bahan baja. Baja merupakan paduan yang terdiri dari besi dan karbon serta unsur lainnya. Baja dapat dibentuk melalui pengecoran atau penempaan. Karbon merupakan salah satu unsur terpenting karena dapat meningkatkan kekerasan dan kekuatan baja. Pada umumnya baja dimanfaatkan dalam bentuk plat, lembaran, pipa, batang, dan profil. Berdasarkan unsur paduannya klasifikasi baja mengikuti AISI (American Iron and Stell Institut).

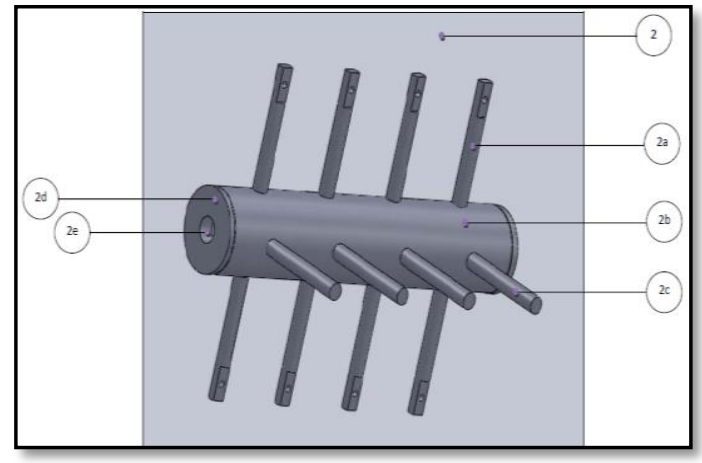

Gambar 2. Pisau Diam

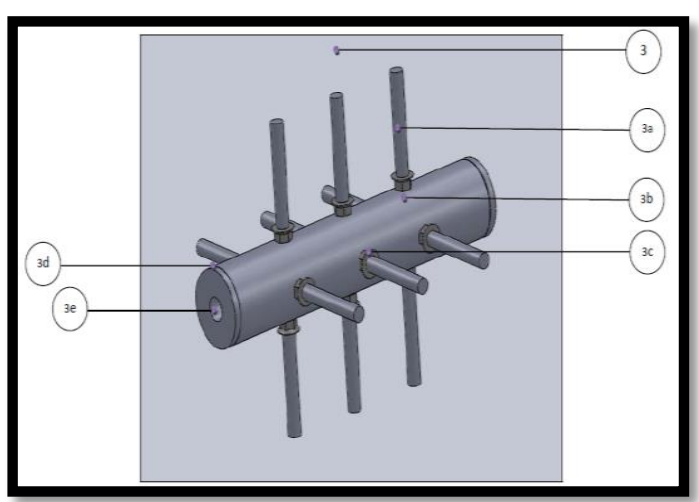

Gambar 3. Pisau Gerak

Proses pembuatan pisau pada mesin ini diawali dengan melakukan proses perancangan pisau diam dan pisau gerak seperti yang disajikan pada Gambar 2 dan

\section{3 |Diselenggarakan dalam rangkaian Dies Natalis Universitas Tanjung Pura Pontianak/tahun/volume}


Seminar Nasional Penerapan Ilmu Pengetahuan dan Teknologi (PIPT)

Gambar 3. Proses perhitungan kekuatan material juga dilakukan untuk memastikan kekuatan material yang digunakan memiliki kekuatan yang cukup untuk menahan pembebanan yang diberikan. Proses terakhir yang dilakukan adalah proses pembuatan pisau sesuai dengan rancangan dan material yang sudah ditentukan. Proses-proses yang dilalui dalam tahapan pembuatan pisau potong ini memiliki tujuan agar pisau yang dibuat bisa berfungsi dengan baik.

\section{Hasil Penelitian dan Pembahasan}

Berdasarkan penelitian yang telah dilakukan didapatkan hasil sebagai berikut:

\section{Menghitung Torsi Pisau}

\section{Pemotong}

$\mathrm{F}=800 \mathrm{~N}$ adalah gaya maksimum yang dibutuhkan untuk memecahkan 1 buah kakao, didapat dari hasil pengujian. $\mathrm{T}=\mathrm{F} \times \mathrm{R}=800 \mathrm{~N} \times 0,14 \mathrm{~m}=$ 112 N.m x $3=336$ N.m

\section{Momen Inersia Pada Pisau}

\section{Pemotong}

$\mathrm{I}=\frac{\pi \cdot d^{4}}{64}=\frac{\pi \cdot(0,02)^{4}}{64}=7,85 \times 10^{-9} \mathrm{~m}^{4}$

\section{Tegangan Lentur Maksimum}

( $\left.\sigma_{\text {LMax }}\right)$ yang Terjadi Pada Pisau

\section{Pemotong}
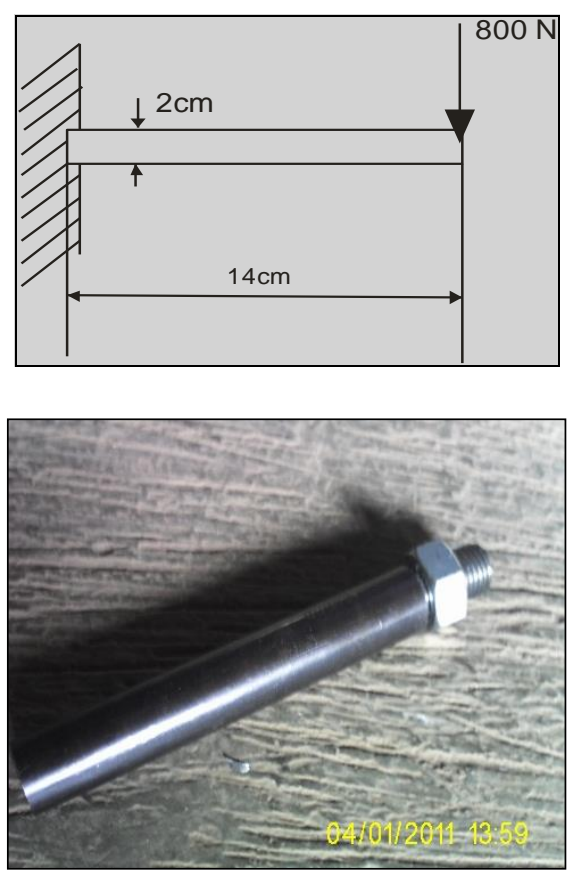

Gambar 4. Tegangan Lentur Pisau Gerak

$$
\begin{aligned}
\mathrm{D} & =2 \mathrm{~cm}=0.02 \mathrm{~m} ; \\
\mathrm{C} & =\frac{1}{2} \cdot \mathrm{D} ; \mathrm{C}=1 \mathrm{~cm}=0.01 \\
\sigma_{\mathrm{L}} & =\frac{M \cdot C}{I}=\frac{112 \times 0,01}{7,85 \times 10^{-9}} \\
& =142,675 \times 10^{6} \mathrm{~N} / \mathrm{m}^{2} \\
& =14,3 \times 10^{6} \frac{\mathrm{kg}}{\mathrm{mm}^{2}}
\end{aligned}
$$

\section{4 |Diselenggarakan dalam rangkaian Dies Natalis Universitas Tanjung Pura Pontianak/tahun/volume}




\section{Dudukan Pisau Mengalami}

\section{Pembebanan Puntir dan lentur}
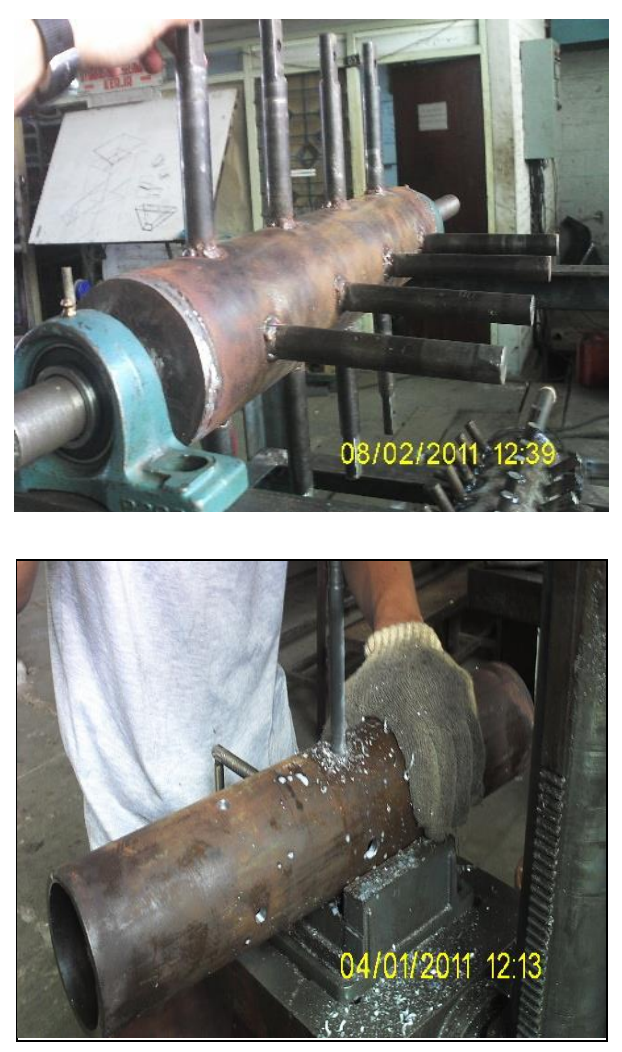

Gambar 5. Dudukan Pisau

Menghitung Momen Inersia Polar

\section{Pada Dudukan Pisau}

$$
\begin{gathered}
\mathrm{I}_{\mathrm{p}}=\frac{\pi \cdot(d o)^{2}-(d 1)^{2}}{32}=\frac{\pi \cdot\left(3,439 \times 10^{-5}\right)}{32} \\
=3,375 \times 10^{-6} \mathrm{~m}^{4} \\
\boldsymbol{\tau}_{\text {max }}=\frac{T \cdot C}{I_{p}} \\
\boldsymbol{\tau}_{\text {max }} \approx 5 \times 10^{6} \frac{\mathrm{N}}{\mathrm{m}^{2}}
\end{gathered}
$$

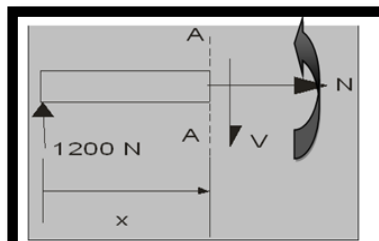

(A)

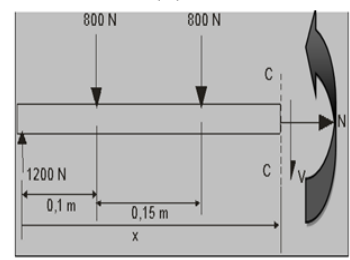

(C)

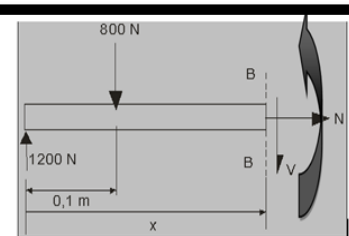

(B)

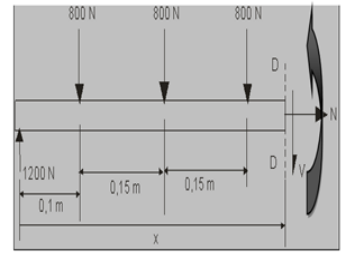

(D)
Gambar 5. Metode Potongan Untuk Mencari Momen Lentur Maksimum Dan Gaya Geser maksimum Pada Dudukan Pisau

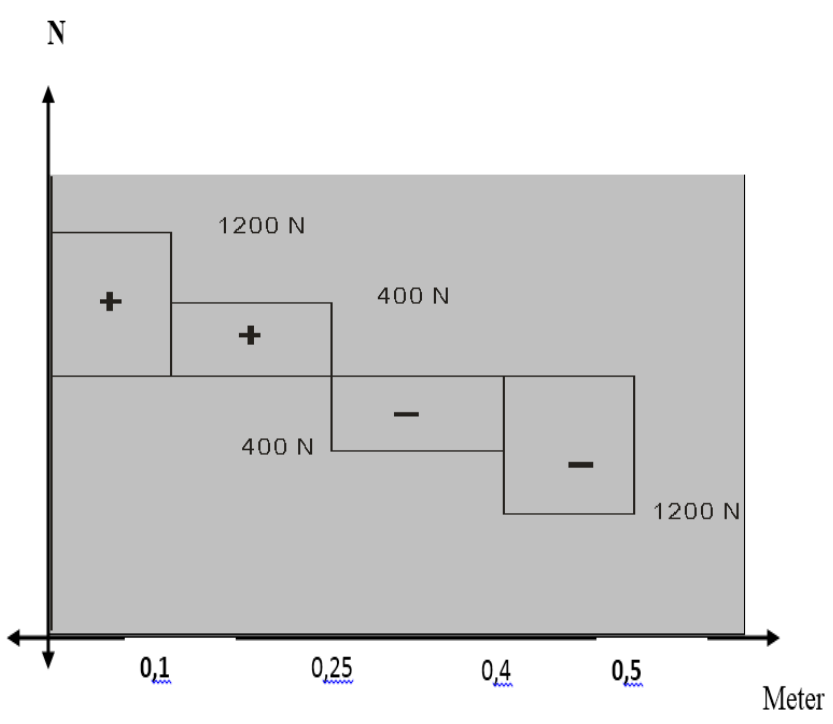

Gambar 6. Diagram Gaya Geser Pada Dudukan Pisau 


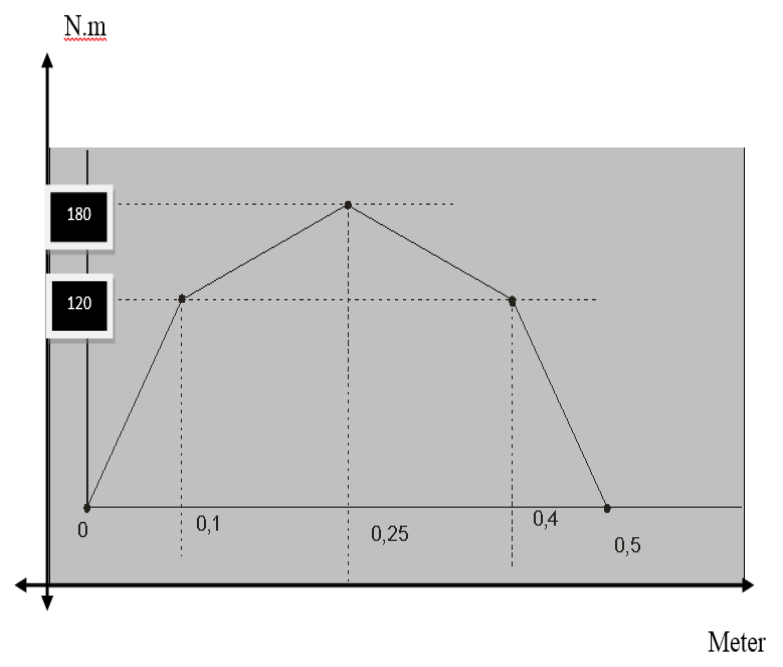

Gambar 7. Diagram Momen Lentur Maksimum Pada Dudukan Pisau

\section{Kesimpulan}

Dari hasil penelitian ini dapat disimpulkan bahwa tegangan lentur maksimum yang terjadi pada pisau potong sebesar $14,3 \times 10^{6} \frac{\mathrm{kg}}{\mathrm{mm}^{2}}$ dan tegangan geser yang terjadi pada pisau potong sebesar $5 \mathrm{x}$ $10^{6} \frac{\mathrm{N}}{\mathrm{m}^{2}}$. Momen lentur maksimum yang terjadi pada dudukan pisau sebesar $180 \mathrm{~J}$ dan gaya geser maksimum yang terjadi pada dudukan pisau sebesar $1200 \mathrm{~N}$.

\section{Ucapan Terima kasih}

Kami sampaikan banyak terima kasih kepada Institut Teknologi Nasional Bandung yang sudah memfasilitasi dalam pembuatan mesin pemecah kakao ini. Semoga Tuhan Yang Maha Kuasa membalas dengan sesuatu hal yang lebih baik dan lebih barokah.

\section{Daftar Pustaka}

Siregar,Tumpal. (2010). Budi Daya Coklat. Penebar Swadaya. Jakarta.

L.Mott Robert (2009), Elemen Elemen Mesin Dalam Perancangan Mekanis Jilid 1 \& 2. Penerbit Andi Yogyakarta.

Arismunandar, Wiranto, Motor Bakar

Torak, Penerbit ITB. Bandung.

Popov.E.P,(1996). Mekanika Teknik.

Penerbit Erlangga. Jakarta.

Beer.P.A,(1996). Mekanika Untuk Insinyur Edisi 4, Penerbit Erlangga. Jakarta.

Dieter.G.E， (1996). Metalurgi Mekanik jilid 1 \& 2 edisi 3, Penerbit Erlangga Jakarta.

Sularso, (1997). Dasar Perancangan

Dan Pemilihan Elemen Mesin.

Penerbit PT Pradnya Pramita. Jakarta.

\section{6 |Diselenggarakan dalam rangkaian Dies Natalis Universitas Tanjung Pura Pontianak/tahun/volume}

